This is a pre-copy-editing, author-produced PDF of an editorial accepted for publication in The International of Therapy and Rehabilitation.

The definitive publisher-authenticated version is: Watson J (2005) Enhancing Student Support to Facilitate Workforce Development. International Journal of Therapy and Rehabilitation. 12(7) p286.

\title{
Enhancing Student Support to Facilitate Workforce Development.
}

\author{
Editorial: \\ International Journal of Therapy \& Rehabilitation
}

\author{
Jo Watson \\ Lecturer in Occupational Therapy \\ School of Health Professions \& Rehabilitation Sciences \\ University of Southampton \\ Highfield, Southampton \\ Hampshire SO17 1BJ
}

Ph: 02380595303

e-mail: jdw@soton.ac.uk

Fax: 02380595301

Word Count: 795 


\section{Introduction}

Reforms of the National Health Service (NHS) incorporate an ambition to expand the occupational therapy (OT) workforce by increasing the number of funded student places by $40 \%$ by 2004 (COT 2003). The aim is not only to increase numbers; but to develop a recruitment base that more closely reflects the cultural diversity of NHS service users and society as a whole (DoH 2000).

Concurrently the government maintains its commitment to widening participation in further and higher education (HE). The vision in this instance is to increase the proportion of 18-30 year olds entering post-compulsory education to $50 \%$ by 2010 through actively promoting participation by all those who stand to benefit, including members of under-represented and disadvantaged groups, rather than simply increasing the numbers of traditional university applicants (DfES 2003).

Against this background there has been an increase in the number of validated OT student places in the UK; although up to 2004, only approximately half of the government's target for the profession was met; and not all of the available places were filled (COT 2003). The profile of OT students is changing with $65 \%$ now aged 21 or older at enrolment and classified as 'mature' students (COT 2003); and an increasing number of students with non-traditional entry qualifications (i.e. non A-level qualifications such as General National Vocational Qualifications, Access Certificates, etc).

\section{Student Experience and Attrition}

Those with non-traditional entry qualifications may experience particular difficulties in making a successful transition to HE based on the different skills, experiences and expectations that they bring with them when compared to school leavers with more traditional A-level qualifications (HEFCE 2001). The first few weeks of year one are particularly challenging to students as they settle into the new environment and begin to understand what is required of them (Hatt \& Baxter 2003). Students can be surprised by the level of responsibility that they are expected to take for their own learning and may find it difficult to adjust to this approach (Brooks 2003), particularly where it is contrary to their previous educational experiences. We cannot assume that all students have developed the necessary academic study skills to succeed in the HE environment before they arrive (Brooks 2003, Hatt \& Baxter 2003).

This phenomenon may of course apply to some A-level entrants, but evidence from non-completion rates would suggest that it is students from nontraditional academic backgrounds who are more likely to withdraw from courses, whether voluntarily or involuntarily due to academic failure (Select Committee on Education \& Employment 2001). Attrition rates within OT programmes are noted to vary between $0-23 \%$ with an average of $10 \%$ (COT 2003); and the government recognises the need for more effective support from within programmes to reduce these figures ( $\mathrm{DoH} 2000)$. 


\section{Supporting Success}

Providing appropriate and effective support to students from non-traditional academic backgrounds is a complex undertaking. Whilst the benefit of suitably focussed induction courses facilitating acclimatisation to the new learning environment are noted, the value of linking study skills support to the curriculum is emphasised in the literature (Webb \& Hill 2003). Hatt \& Baxter (2003) particularly highlight that in order to succeed students need to understand the rules and practices of the new learning environment within the context of the tasks and activities that are required of them.

Emerging evidence of good practice seems to suggest that an ongoing, multifaceted approach to supporting non-traditional students is likely to be far more effective than the implementation of a single discrete activity (HEFCE 2003). In addition to effective induction and ongoing study skills support, investment in quality enhancement strategies such as comprehensive pre-registration information, regular pastoral support, access to appropriate child care and financial support, flexible patterns of study and the development of learning environments that recognise and respect the diversity of the student population all have the potential to exert positive influences on retention without lowering academic standards, to the benefit of all students (Brooks 2003, HEFCE 2001).

\section{Developing the Workforce}

Widening participation agendas and the drive to expand the NHS workforce present educators with a responsibility for not only recruiting students from increasingly diverse backgrounds; but for providing appropriate mechanisms to retain and support these students through to graduation whilst maintaining standards. Policies that grant admission to programmes, and then allow it to be followed by preventable failure would be difficult to defend. Although not directly applicable to OT students, the new fee-paying environment is likely to have a considerable impact on the way students select programmes of study and the institutions to which they apply. Focussing on the development of high quality student-centred programmes has the potential to not only meet the primary aim of addressing attrition rates, but may also encourage more students to consider studying OT. The profession and its workforce have much to gain either way. 


\section{References:}

Brooks, R. (2003) The Experiences of Non-Traditional Students at the University of Surrey. Department of Educational Studies, University of Surrey.

College of Occupational Therapists (2003) Ten Year Review of Occupational Therapy Student Numbers in the United Kingdom. London: College of Occupational Therapists.

Department of Health (2000) Meeting the Challenge: A Strategy for the Allied Health Professions. London: Department of Health.

Department for Education and Skills (2003) The Future of Higher Education. London: Department for Education \& Skills.

Hatt, S. \& Baxter, A. (2003) From FE to HE: Studies in Transitions: A Comparison of Students Entering Higher Education with Academic and Vocational Qualifications. Widening Participation and Lifelong Learning, 5 (2), 18-29.

Higher Education Funding Council for England (2003) Review of 2001 Widening Participation Strategies and Action Plans from HEls. Bristol: Higher Education Funding Council for England.

Higher Education Funding Council for England (2001) Strategies for Widening Participation in Higher Education: A Good Practice Guide. Bristol: Higher Education Funding Council for England.

Select Committee on Education and Employment (2001) Select Committee on Education and Employment: Sixth Report - Higher Education: Student Retention. Available at:

http://www.publications.parliament.uk/pa/cm/cmeduemp.htm Accessed: 10/07/2004.

Webb, M. \& Hill, M. (2003) The Institution Gets its Act Together: Linking Learning \& Teaching and Widening Participation Strategies to Improve Completion Rates. Widening Participation and Lifelong Learning, 5 (3), 46-49. 